\begin{tabular}{ll} 
Bentham open & The Open Dentistry Journal \\
CrossMark & Content list available at: www.benthamopen.com/TODENTJ/ \\
\hline
\end{tabular}

RESEARCH ARTICLE

\title{
Effect of Denture Adhesives in New Complete Dentures During a Function
}

Diego Mourão Guimarães, Érika Justo Marques, Giulia Cristina Deiró Almagro, Carolina Mayumi Iegami ${ }^{*}$, Roberto Chaib Stegun and Marcio Katsuyoshi Mukai

Department of Prosthodontics, School of Dentistry, University of Sao Paulo, Sao Paulo, SP, Brazil

Received: April 17, 2018

Revised: October 11, 2018

Accepted: October 29, 2018

\section{Abstract:}

Background:

Denture adhesives are often a matter of controversy. Patients seem to easily accept the use of denture adhesives, while professionals are more hesitant.

\section{Objective:}

The purpose of this study was to evaluate the self-perception, bite force and masticatory efficiency of complete denture wearers with denture adhesives.

\section{Methods:}

Fifteen complete denture wearers had their bite force measured by a gnathodynamometer in the molar region. Subjects also masticated 12 tablets of a chewable artificial test material for 35 masticatory cycles. The test material was washed, dried, sieved and weighed. Both tests were taken with and without the denture adhesive (Corega Ultra). The questionnaire Geriatric Oral Health Assessment Index (GOHAI) was applied to evaluate self-perception with dentures.

\section{Results and Conclusion:}

Masticatory efficiency and bite force for the control group (without denture adhesive) and for the group with denture adhesive presented no statistically significant differences ( $p=0.2080$ and $p=0.2489$, respectively). Self-perception according to the GOHAI index was great for $13 \%$ of participants, $40 \%$ considered it regular and $47 \%$ evaluated it as bad. Within the limitations of this study, it can be concluded that the use of denture adhesive did not promote an improvement in bite force and masticatory efficiency. According to the GOHAI index, self-perception of the participants was classified as bad.

Keywords: Complete denture, Bite force, Mastication, Patient satisfaction, GOHAI index, Denture adhesives.

\section{INTRODUCTION}

Tooth loss affects the world population and has psychological and quality of life implications, especially in elderly subjects [1 - 3]. Some of those are self-image issues, social interaction and psychological health [4]. Tooth loss also affects the stomatognathic system. Aesthetics, speech function and masticatory force and efficiency decrease, leading to general health problems for the subject.

Adequate complete denture therapy contributes to enhance the oral health status for the subject, however, when the patient presents severely resorbed alveolar ridges or does not have proper neuromotor skills, the use of denture adhesive can be prescribed [5 - 7]. Denture adhesives are often the matter of controversy. Patients seem to easily accept the use

\footnotetext{
* Address correspondence to this author at the Department of Prosthodontics, School of Dentistry, University of Sao Paulo, Avenida Professor Lineu Prestes, 2227, Cidade Universitária 05508-000, Sao Paulo, Brazil; Tel: 5511 2648-8321; Fax: 55 11 3091-7888; E-mail: carolinaiegami@usp.br
} 
of denture adhesives. Some even consider the use of denture adhesives as part of the treatment. Self-perception studies report that while wearing dentures with adhesive, comfort and satisfaction were increased [8 - 10]. Professionals, however, are more hesitant. It is believed by the dental community that misuse of the adhesive might increase occlusion vertical dimension, that its continuous use might mask tissue changes, which can be deleterious for the remaining bone, also that denture adhesives are not required for well-fitted dentures [11]. Some are considered myths, others truth, but the controversy still exists between dentists. The use of adhesives is advertised as an aid to avoid embarrassing situations while speaking or eating, for example. Patients usually rely on its use despite being informed by their dentists that the well-fitted denture does not require adhesives.

Denture adhesives are available in the market in the form of pads, synthetic wafers, creams, pastes and powders. Synthetic wafers and pads are soluble, while pastes, creams and powders are insoluble [11]. There is no consensus in the literature as one type of adhesive being better than others [9].

The aim of this study was to analyze satisfaction, masticatory force and efficiency of complete denture wearers with denture adhesives.

\section{MATERIALS AND METHODS}

Fifteen participants were selected from a group of edentulous subjects that received dentures from the University of Sao Paulo - School of Dentistry. Inclusion criteria were as follows: Healthy maxillary and mandibular complete denture wearers fully adapted to their dentures for at least 2 months prior to the study. These subjects were rehabilitated according to the protocols in the prosthodontics clinic of the Department of Prosthodontics of the University of Sao Paulo - School of Dentistry. This study was approved by the local ethics committee, under the protocol: CAAE45537115.7.0000.0075.

Subjects with temporomandibular or motor/orofacial disorders, xerostomia, severe systemic diseases, psychological and psychiatric problems were excluded.

For a subjective assessment, all participants answered a Geriatric Oral Health Assessment Index (GOHAI) questionnaire [12].

Participants were instructed to stand still on both feet in erect position [13]. A gnatodynamometer (Kratos) was positioned between molars on both sides of the mouth and the subject was instructed to bite while wearing dentures Without Adhesive (WA). After that, participants would chew 12 Optocal cylinders for 35 masticatory cycles. Force and masticatory tests were repeated when subjects were wearing Dentures with Adhesive (DA) (Corega Ultra Creme ${ }^{\circledR}$, GlaxoSmith Kline Brasil Ltda, Rio de Janeiro, RJ, Brazil). The denture adhesive was composed by Poly (methlvinylether/maleic acid) sodium-calcium mixed partial salt, petrolatum, cellulose gum and paraffinum liquidum.

Optocal cylinders were made up of 58,3\% of condensed silicon (Optosil Comfort, Heraeus Kulzer GmbH \& Co. KG, Germany), 12.5\% alginate powder (Jeltrate, Dentsply Indústria e Comércio Ltda, Petrópolis, RJ, Brazil), 11.5\% of solid Vaseline (Rioquímica, São José do Rio Preto, SP, Brazil)10.2\% dental plaster powder (Mossoró, Empresa e Indústria Gesso Mossoró SA, Rio de Janeiro, RJ, Brazil), 7.5\% toothpaste (Colgate-Palmolive, Co. Osasco, SP, Brazil) and $20.8 \mathrm{mg}$ of catalyst paste (Optosil Comfort, Heraeus Kulzer GmbH \& Co. KG, Germany) [14]. Ingredients were weighed on a digital scale (Marte model AS5500), mixed according to the indicated quantities and inserted in a standardized acrylic mold. Optocal cylinders presented $12 \mathrm{~mm}$ in diameter by $5 \mathrm{~mm}$ width.

Each chewed sample was washed in order to remove saliva and then dried for 1 hour at $80{ }^{\circ} \mathrm{C}$. An Optocal particle analysis was conducted through sieving the material with four different mesh size sieves (1 mm, $2 \mathrm{~mm}, 2.8 \mathrm{~mm}, 4 \mathrm{~mm})$, under vibration for 2 minutes. The residue of each sieve was weighed on a precision scale and the values were compared to its original weight. When the difference between the two was superior to $6 \%$, the test was retaken [14].

Masticatory performance was calculated as the weight of comminuted material that passed through the $2.8 \mathrm{~mm}$ sieve [15], according to the method suggested by Yurkstas and Manly [16], where the volume of test food passing through a sieve, divided by the total volume recovered resulted in the masticatory efficiency. Statistical analysis of the collected data was performed with Biostat Software version 5.4, 1-way ANOVA was applied to the results.

\section{RESULTS}

Masticatory efficiency for DA and WA groups was $43 \%$ and $30 \%$, respectively. 1-way ANOVA for paired samples was performed and no statistically significant difference was observed between groups $(p=0,2098)$ (Table 1). 
Table 1. 1-way ANOVA test comparing masticatory efficiency of WA and DA groups.

\begin{tabular}{|c|c|c|}
\hline- & WA & DA \\
\hline Sample size $=$ & 15 & 15 \\
\hline Mean $=$ & 0.30 & 0.43 \\
\hline Standard Deviation= & 0.29 & 0.24 \\
\hline $\mathrm{F}=$ & 1.6307 & - \\
\hline$(\mathrm{p})=$ & 0.2098 & - \\
\hline
\end{tabular}

The masticatory force was $5.3 \mathrm{Kgf}$ and $4 \mathrm{Kgf}$ for DA and WA, respectively (Table 2).

Table 2. 1-way ANOVA test comparing masticatory force in WA and DA groups.

\begin{tabular}{|c|c|c|}
\hline- & WA & 15 \\
\hline Sample size $=$ & 0.40 & 15 \\
\hline Mean $=$ & 3.15 & 0.53 \\
\hline Standard Deviation $=$ & 1.3748 & 3.09 \\
\hline $\mathrm{F}=$ & 0.2489 & - \\
\hline$(\mathrm{p})=$ & - & \\
\hline
\end{tabular}

1-way ANOVA test result shows that there is no statistically significant difference between groups $(p=0.2489)$.

GOHAI score analysis showed that $47 \%, 40 \%$ and $13 \%$ of the participants presented low, fair and high levels of oral health, respectively (Table 3 ).

Table 3. Answers given by the elderly according to each GOHAI question.

\begin{tabular}{|c|c|c|c|}
\hline GOHAI QUESTIONNAIRE & - & - & - \\
\hline In the past three mouths & Always & Sometimes & Never \\
\hline 1- How often did you limit types or amounts of food you eat because of problems with your teeth or denture? & 4 & 6 & 5 \\
\hline 2- How often did you have trouble biting or chewing any kinds of food, such as firm meats or apples? & 6 & 3 & 6 \\
\hline 3- How often were you able to swallow comfortably? & 9 & 1 & 5 \\
\hline 4- How often have your teeth or dentures prevented you from speaking the way you wanted? & 4 & 4 & 7 \\
\hline 5- How often were you able to eat anything without feeling discomfort? & 3 & 6 & 6 \\
\hline 6- How often did you limit contacts with people because of the condition of your teeth or denture? & 1 & 5 & 9 \\
\hline 7- How often were you pleased or happy with the looks of your teeth, gums or denture? & 6 & 5 & 4 \\
\hline 8- How often did you use medication to relieve mouth pain or discomfort? & 0 & 5 & 10 \\
\hline 9- How often were you worried or concerned about teeth, gums or denture problems? & 2 & 5 & 8 \\
\hline 10- How often did you feel nervous or self-conscious because of problems with your teeth, gums or denture? & 1 & 4 & 10 \\
\hline 11- How often did you feel uncomfortable eating in front of people because teeth or denture problems? & 1 & 4 & 10 \\
\hline 12- How often were your teeth or gums sensitive to hot, cold or sweets? & 3 & 3 & 9 \\
\hline
\end{tabular}

\section{DISCUSSION}

Masticatory force is the result of the coordination between different components of the masticatory system. Statistical analysis indicates that the use of denture adhesives was not relevant in this study. The test was executed in the molar area, assessing the maximum bite force in the region. This result was expected since denture adhesives are required especially when the denture is moved in the cervico-occlusal direction. Another study found similar results [7] while analyzing occlusal forces at the dislodgement in the pre-molar area. There were no statistical differences between WA and DA groups. However, a previous study that evaluated anterior teeth bite force presented statistically significant differences between groups [17].

The artificial test food "Optocal "was chosen over natural food for masticatory tests to standardize sample sizes and weight. The natural food contains water, which might affect the results after the processing and drying of the test foods [18]. However, real food might psychologically influence mastication, thus the particle distribution could have been different [19]. The number of chewing strokes was set at 35 cycles for standardization. It has been shown that the number of chewing cycles needed to swallow varies among people. If tests were performed with chewing until swallowing, the material distribution could also have been different [19].

According to the GOHAI scores, the majority of the participants presented low or fair levels of perceived oral 
health. Eighty percent of the subjects answered that they sometimes or never were able to eat any type of food without feeling discomfort in the last few months. This statistic represents a major complaint with complete dentures: Mobility during mastication. The use of denture adhesives should provide more stability and retention to the denture, as well as confidence during mastication [11]. Some authors [20,21] also observed an increase in the masticatory performance of denture wearers by using different denture adhesives in comparison with control groups (WA).

However, results in this study show that there was no statistically significant difference between WA and DA groups when masticatory efficiency is concerned. One might infer that the sample size of participants may have contributed to this statistical result since other authors have found different results $[9,15]$. Nevertheless, there are studies with similar sample sizes that present different results as well [7, 15, 22]. Another study observed that denture adhesives results are more expressive for poor denture-bearing tissues and for ill-fitted dentures [21]. In this study, patients were fully adapted to their new complete dentures, which might have contributed to the absence of significant difference between groups.

GOHAI questionnaire results are similar to another study with a similar population [23]. Sixty percent of the participants did not avoid social contact nor felt discomfort when swallowing food. Sixty-seven percent did not relate issues when eating in front of other people, which can be considered great from the social and psychological aspects. The same value was obtained when participants were asked if they used denture pain relief medicines, confirming that they did not need to take these.

\section{CONCLUSION}

Within the limitations of this preliminary study, it can be concluded that the use of denture adhesive did not promote an improvement in bite force and masticatory efficiency. The average index GOHAI test self-perception of the participants was classified as bad.

\section{ETHICS APPROVAL AND CONSENT TO PARTICIPATE}

This study was approved by the local ethics committee (University of Sao Paulo - School of Dentistry) under the protocol: CAAE45537115.7.0000.0075.

\section{HUMAN AND ANIMAL RIGHTS}

No animals were used in this research. All research procedures followed were in accordance with the ethical standards of the committee responsible for human experimentation (institutional and national), and with the Helsinki Declaration of 1975, as revised in 2013.

\section{CONSENT FOR PUBLICATION}

All participants answered a Geriatric Oral Health Assessment Index (GOHAI) questionnaire.

\section{CONFLICT OF INTEREST}

The authors declare no conflict of interest, financial or otherwise.

\section{ACKNOWLEDGEMENT}

Declared none.

\section{REFERENCES}

[1] Ettinger RL. Oral disease and its effect on the quality of life. Gerodontics 1987; 3(3): 103-6. [PMID: 3305120]

[2] Leao A, Sheiham A. The development of a socio-dental measure of dental impacts on daily living. Community Dent Health 1996 ; $13(1)$ : 22-6. [PMID: 8634892]

[3] Hazari P, Bhoyar A, Mishra SK, Yadav NS, Mahajan H. A comparison of masticatory performance and efficiency of complete dentures made with high impact and flexible resins: A pilot study. J Clin Diagn Res 2015; 9(6): ZC29-34.

[PMID: 26266213]

[4] Davis DM, Fiske J, Scott B, Radford DR. The emotional effects of tooth loss: A preliminary quantitative study. Br Dent J 2000; 188(9): 503-6.

[PMID: 10859849] 
[5] Kelsey CC, Lang BR, Wang RF. Examining patients' responses about the effectiveness of five denture adhesive pastes. J Am Dent Assoc 1997; 128(11): 1532-8. [http://dx.doi.org/10.14219/jada.archive.1997.0093] [PMID: 9368438]

[6] Sato H, Fueki K, Sueda S, et al. A new and simple method for evaluating masticatory function using newly developed artificial test food. J Oral Rehabil 2003; 30(1): 68-73. [http://dx.doi.org/10.1046/j.1365-2842.2003.01049.x] [PMID: 12485386]

[7] Polyzois G, Partalis C, Lagouvardos P, Polyzois H. Effect of adaptation time on the occlusal force at denture dislodgement with or without denture adhesive. J Prosthet Dent 2014; 111(3): 216-21. [http://dx.doi.org/10.1016/j.prosdent.2013.06.020] [PMID: 24331849]

[8] Kulak Y, Ozcan M, Arikan A. Subjective assessment by patients of the efficiency of two denture adhesive pastes. J Prosthodont 2005; 14(4): 248-52. [http://dx.doi.org/10.1111/j.1532-849X.2005.00049.x] [PMID: 16359481]

[9] Papadiochou S, Emmanouil I, Papadiochos I. Denture adhesives: A systematic review. J Prosthet Dent 2015; 113(5): 391-7.e2. [http://dx.doi.org/10.1016/j.prosdent.2014.11.001] [PMID: 25749085]

[10] Bekiroglu N, Çiftçi A, Bayraktar K, Yavuz A, Kargul B. Oral complaints of denture-wearing elderly people living in two nursing homes in Istanbul, Turkey. Oral Health Dent Manag 2012; 11(3): 107-15. [PMID: 22976570]

[11] Grasso JE. Denture adhesives. Dent Clin North Am 2004; 48(3): 721-33, vii. [http://dx.doi.org/10.1016/j.cden.2004.04.002] [PMID: 15261802]

[12] Atchison KA, Dolan TA. Development of the geriatric oral health assessment index. J Dent Educ 1990; 54(11): 680-7. [PMID: 2229624]

[13] Farias Neto A, Mestriner Junior W, Carreiro AdaF. Masticatory efficiency in denture wearers with bilateral balanced occlusion and canine guidance. Braz Dent J 2010; 21(2): 165-9. [http://dx.doi.org/10.1590/S0103-64402010000200013] [PMID: 20640365]

[14] Pocztaruk RdeL, Frasca LCF, Rivaldo EG, Fernandes EdeL, Gavião MBD. Protocol for production of a chewable material for masticatory function tests (Optocal - Brazilian version). Braz Oral Res 2008; 22(4): 305-10. [http://dx.doi.org/10.1590/S1806-83242008000400004] [PMID: 19148384]

[15] de Oliveira Junior NM, Rodriguez LS, Mendoza Marin DO, Paleari AG, Pero AC, Compagnoni MA. Masticatory performance of complete denture wearers after using two adhesives: A crossover randomized clinical trial. J Prosthet Dent 2014; $112(5)$ : $1182-7$. [http://dx.doi.org/10.1016/j.prosdent.2014.05.004] [PMID: 24952882]

[16] Yurkstas A, Manly RS. Value of different test foods in estimating masticatory ability. J Appl Physiol 1950; $3(1)$ : 45-53. [http://dx.doi.org/10.1152/jappl.1950.3.1.45] [PMID: 14774321]

[17] Kalra P, Nadiger R, Shah FK. An investigation into the effect of denture adhesives on incisal bite force of complete denture wearers using pressure transducers - a clinical study. J Adv Prosthodont 2012; 4(2): 97-102. [http://dx.doi.org/10.4047/jap.2012.4.2.97] [PMID: 22737315]

[18] Slagter AP, Olthoff LW, Steen WHA, Bosman F. Comminution of food by complete-denture wearers. J Dent Res 1992; 71(2): 380-6. [http://dx.doi.org/10.1177/00220345920710020601] [PMID: 1556296]

[19] Iegami CM, Barbosa WF, Furuyama RJ, et al. Masticatory efficiency in complete denture wearers with reduced dental arches: A randomised cross-over study. J Oral Rehabil 2014; 41(8): 619-23. [http://dx.doi.org/10.1111/joor.12179] [PMID: 24779746]

[20] Neill DJ, Roberts BJ. The effect of denture fixatives on masticatory performance in complete denture patients. J Dent 1973; 1(5): 219-22. [http://dx.doi.org/10.1016/0300-5712(73)90064-X] [PMID: 4594136]

[21] Fujimori T, Hirano S, Hayakawa I. Effects of a denture adhesive on masticatory functions for complete denture wearers: Consideration for the condition of denture-bearing tissues. J Med Dent Sci 2002; 49(4): 151-6. [PMID: 12641386]

[22] Torres-Sánchez C, Montoya-Salazar V, Torres-Lagares D, Gutierrez-Pérez JL, Jimenez-Castellanos E. Comparison of masticatory efficacy among complete denture wearers with two adhesives and dentate individuals: A randomized, crossover, double-blind clinical trial. J Prosthet Dent 2017; 117(5): 614-20. [http://dx.doi.org/10.1016/j.prosdent.2016.09.020] [PMID: 27914670]

[23] Henriques C, Telarolli Júnior R, Loffredo LCM, Montandon AAB, Campos JADB. Autopercepção das condições de saúde bucal de idosos do município de Araraquara: SP. Cienc Odontol Bras 2007; 10: 67-73.

(C) 2018 Guimarães et al.

This is an open access article distributed under the terms of the Creative Commons Attribution 4.0 International Public License (CC-BY 4.0), a copy of which is available at: (https://creativecommons.org/licenses/by/4.0/legalcode). This license permits unrestricted use, distribution, and reproduction in any medium, provided the original author and source are credited. 